Article

\title{
Fungicides Films of Low-Density Polyethylene (LDPE)/Inclusion Complexes (Carvacrol and Cinnamaldehyde) Against Botrytis Cinerea
}

\author{
Daniel Canales ${ }^{1}$, Lissette Montoille ${ }^{1}$, Lina M. Rivas ${ }^{2}$, J. Andrés Ortiz ${ }^{1}$, Mauricio Yañez-S ${ }^{3}$, \\ Franco M. Rabagliati ${ }^{1}$, Maria Teresa Ulloa ${ }^{2}$, Eduardo Alvarez ${ }^{2}$ iD and Paula A. Zapata ${ }^{1, *}$ \\ 1 Grupo Polímeros, Facultad de Química y Biología, Universidad de Santiago de Chile, USACH, Casilla 40, \\ Correo 33, Santiago 9170022, Chile; daniel.canalesarevalo@gmail.com (D.C.); li.montoille@gmail.com (L.M.); \\ jonathan.ortizn@usach.cl (J.A.O.); franco.rabagliati@usach.cl (F.M.R.) \\ 2 Programa de Microbiología y Micología, ICBM Facultad de Medicina Universidad de Chile, \\ Avenida Independencia 1027, Independencia, Santiago 8380000, Chile; lrivas734@gmail.com (L.M.R.); \\ mtulloa@med.uchile.cl (M.T.U.); ealvarezd@med.uchile.cl (E.A.) \\ 3 Laboratorio de biopolímeros, Departamento de Ciencias del Ambiente, Universidad de Santiago de Chile, \\ USACH, Casilla 40, Correo 33, Santiago 9170022, Chile; mauricio.yanez@usach.cl \\ * Correspondence: paula.zapata@usach.cl
}

Received: 24 October 2019; Accepted: 22 November 2019; Published: 26 November 2019

\begin{abstract}
Low density polyethylene (LDPE) films were prepared with the incorporation of natural agents (carvacrol and trans-cinnamaldehyde) by the melting process. The co-precipitation method was used successfully to complex the carvacrol or trans-cinnamaldehyde with $\beta$-cyclodextrin $(\beta-C D)$. The active compounds encapsulated in $\beta-\mathrm{CD}$ achieved ca. 90\% encapsulation efficiency (E.E.). The inclusion complex studied by scanning electron microscopy (SEM) found particles of different sizes, ca. $4 \mu \mathrm{m}$. The active compounds were added directly ( 1 and $5 \mathrm{wt} \%$ ) into the polymer matrix, yielding LDPE + carvacrol and LDPE + cinnamaldehyde films. The active compounds encapsulated in $\beta$-cyclodextrin $(\beta-C D)$ were added to LDPE, yielding LDPE $+\beta$-CD-carvacrol and LDPE $+\beta$-CD-cinnamaldehyde films. The incorporation of carvacrol and trans-cinnamaldehyde, and their corresponding inclusion complexes with $\beta$-cyclodextrin, did not affect the thermal properties of LDPE. The microcapsules distributed in all polymer matrices had sizes of 5-20 $\mu \mathrm{m}$ as shown by scanning electron microscopy (SEM). In terms of mechanical properties, the polymers showed a slight decrease of Young's modulus $(12 \%)$ and yield stress compared $(14 \%)$ to neat LDPE. This could be due to the essential oil acting as a plasticizer in the polymer matrix. The LDPE + carvacrol and LDPE + cinnamaldehyde films had the capacity to inhibit fungi by $99 \%$ compared to neat LDPE. The effectiveness against fungi of LDPE $+\beta-C D+$ active agent was slower than by the direct incorporation of the essential oil in the LDPE in the same amount of active agent. The biocidal properties were related to the gradual release of active compound from the polymer. The results confirm the applicability of carvacrol, trans-cinnamaldehyde, and their corresponding inclusion complexes in active packaging, as well as their use in the food delivery industry.
\end{abstract}

Keywords: essential oil; carvacrol; cinnamaldehyde; $\beta$-cyclodextrin; inclusion complexes; Botrytis cinerea; antimicrobial packaging

\section{Introduction}

The deterioration of fruits caused by the action of pathogenic microorganisms like Botrytis cinerea can cause gray rot in grapes. This produces significant economic loss in vineyards around the world and particularly in Chile [1,2]. The production and export of Chilean fruit has increased in the last two 
decades, positioning Chile among the largest exporters of fresh fruit in the world. Table grapes stand out, corresponding to $32 \%$ of the total exported from Chile. However, the losses caused by the action of Botrytis cinerea during export can reach 30\% [3,4]. Therefore, it is necessary to obtain an active food packaging for table grapes that prevents deterioration during transport.

Food industry challenges are focused on diverse requirements set by consumers, or by the industry itself, and one of the most important of these is the growing interest in preserving food quality from sensory and nutritional standpoints without increasing production costs [5]. It is important to search for antimicrobial agents that can protect food from foreign agents. Active packaging provides an inert barrier against external conditions to prolong the useful life of the food; it differs from traditional passive packaging, which only provides protection and barrier functions. Active packaging contains preservatives incorporated directly into the packaging material, offering advantages over the preservatives used directly on the food, since the amount of preservatives in contact with the food is lower [6]. In this context, polyethylene (PE) composites appear as viable materials aimed at improving the behavior of traditional PE films. The products used as antimicrobial packaging materials are essential oils or metal particles [7]. Several studies have been reported based on polyethylene as a matrix with the incorporation of organic and inorganic nanoparticles as active agents. The preparation of nanocomposites based on polyethylene (PE) with the incorporation of nanoparticles such as silver (10 nm, $5 \mathrm{wt} \%$ ) [8], copper (10-40 nm, $5 \mathrm{wt} \%), \mathrm{TiO}_{2}$ [9], or $\mathrm{ZnO}$ [10] has been reported. The nanocomposites with silver and copper incorporation show biocidal activity close to $99.9 \%$ against Escherichia coli [11], but these nanoparticles have some disadvantages that have not been reported, such as innocuity and toxicity in humans. $\mathrm{TiO}_{2}(10 \mathrm{~nm}, 3-8 \mathrm{wt} \%)$ has also been incorporated into $\mathrm{PE}$ in order to obtain food packaging with biocidal properties against $E$. coli. The nanocomposites containing $8 \mathrm{wt} \%$ of modified $\mathrm{TiO}_{2}$ nanoparticles were effective against $E$. coli bacteria, killing $99.9 \%$ compared to pure PE. The main disadvantage of $\mathrm{TiO}_{2}$ nanoparticles is that they require UV light in order to release the active species responsible for their biocidal properties [12-14]. Therefore, the use of natural products is a new route in order to produce PE with biocidal properties, such as essential oils (EO), which can be obtained from plants with a composition rich in terpenoids and phenolics among others [15]. In addition to essential oils, several natural extracts, particularly from agricultural food waste, have been used in food packaging [16]. Experimental essential oils (EOs) are among the most important raw materials in the food and pharmaceutical industry [17]. They can be extracted from various aromatic plants that synthesize them [18]. These essential oils, in particular cinnamon and oregano, possess various biological activities, mainly antibacterial, antifungal, and antioxidant properties, with potential applications in packaging [19-21].

Cinnamon and oregano are two essential oils whose main active principles are cinnamaldehyde and carvacrol, respectively. Cinnamon is used mainly in cooking as a condiment and flavoring material. Furthermore, they are high in antioxidant activity and have antimicrobial properties [22]. From cinnamon extract, trans-cinnamaldehyde has been found to be one of the most effective antioxidant and antimicrobial agents against foodborne pathogens [23]. The essential oil of oregano consists mainly of carvacrol and thymol, whose amounts vary depending on origin [24]. Carvacrol, a monoterpene phenol, can be found from traces up to $80 \%$ in various species [25]. It has excellent antioxidant and antimicrobial properties; the antibacterial activity of carvacrol has been attributed to its considerable effects on the structural and functional properties of cytoplasm membranes [15]. However, the essential oil decomposes or is evaporated when exposed to air, light or heat. One way to stabilize the essential oil is by its inclusion in carrier molecules [17]. The molecular encapsulation of essential oils upgrades their chemical and thermal stability and facilitates their handling [19]. Encapsulation can be achieved by complexation with cyclodextrins (CD). The inclusion complex guest compound with $\mathrm{CD}$ can enhance stability, improve water solubility, protect against oxidation and heat, and reduce volatility [17]. Cyclodextrins are enzymatically modified starch and macrocyclic oligosaccharides, consisting of $(\alpha-1,4)$-linked $\alpha$-D-glucopyranose units, with a hydrophilic outer surface and a hollow hydrophobic interior [26]. CDs have the ability to form inclusion complexes with hydrophobic 
molecules such as essential oils, which go partly or entirely into the relative hydrophobic cavity of the $\mathrm{CD}$, expelling at the same time the few high energy water molecules from the inside [27]. Petrovic et al. prepared the inclusion complex of cinnamon with $\beta$-CD using the coprecipitation method [22]. The authors showed that the main components studied chromatographically were $(E)$-cinnamaldehyde, (Z)-cinnamaldehyde, and eugenol. The essential oil was complexed with $\beta-C D$ with a $93.77 \%$ yield. The ratio of $\beta-C D$ to active agents was 80:20 (w/w).

Wen et al. [28] studied the incorporation of an inclusion complex of cinnamon essential oil (CEO) with $\beta$-cyclodextrin into poly (lactic acid) (PLA) by an electrospinning technique. The PLA/CEO/ $\beta$-CD films showed antimicrobial activity against E. coli and Staphylococcus aureus. The authors suggest that PLA/CEO/ $\beta-C D$ nanofilm could be effective in order to prolong the shelf life of packaged pork food. Chen et al. [29] studied the antimicrobial activity of films using sulfated cellulose as polymer matrix and mustard essential oil (MEO) complexed previously with $\beta-\mathrm{CD}$ ( $\beta$-CD-active agent). The films showed less transparency and water absorption, but high inhibition rate, reaching $99 \%$ against E. coli. Nostro et al. [25] studied the antimicrobial and antibiofilm properties of films based on poly(ethylene-co-vinyl acetate) (EVA) with carvacrol and trans-cinnamaldehyde. The polymeric films were prepared with $3.5 \mathrm{wt} \%$ and $7 \mathrm{wt} \%$ of filler by the melting process. The films with $7 \mathrm{wt} \%$ of both active agents had bactericidal effects (reduction of 4 and $2 \log$ CFU) against S. aureus and E. coli, and a bacteriostatic effect against Staphylococcus epidermidis and Listeria monocytogenes (reduction of about $1 \log$ CFU). Regarding biofilm formation; the biomass formed on the polymer's film surface was significantly reduced compared to the pure copolymer control.

There are no reports related to the effect of the incorporation of active compounds (carvacrol and trans-cinnamaldehyde) in low density polyethylene (LDPE) against $B$. cinerea. Therefore, carvacrol or trans-cinnamaldehyde were incorporated in different percentages $(5 \mathrm{wt} \%)$ directly into LDPE by the melting process, obtaining the LDPE + carvacrol and LDPE + cinnamaldehyde films. The active agents (carvacrol or trans-cinnamaldehyde) were also complexed with $\beta$-CD before being incorporated into LDPE, obtaining the LDPE $+\beta$-CD-active agent films ( $1 \mathrm{wt} \%$ of carvacrol or trans-cinnamaldehyde). The thermal and mechanical properties of the films were analyzed. The agent's active release over time and the fungicidal activity of the films against $B$. cinerea were also studied. These composites could be attractive to be used as food packaging in special Chilean table grapes.

\section{Experimental}

\subsection{Materials}

LDPE pellets, map $=116{ }^{\circ} \mathrm{C}, \mathrm{d}=0.93 \mathrm{~g} / \mathrm{mL} ; \beta$-Cyclodextrin $(97 \%), \mathrm{MW}=1139.98 \mathrm{~g} / \mathrm{mol}$; Carvacrol (99\%) $\mathrm{MW}=150.22 \mathrm{~g} / \mathrm{mol}, \mathrm{d}=0.977 \mathrm{~g} / \mathrm{mL}$, at $25^{\circ} \mathrm{C}$; and trans-cinnamaldehyde $(95 \%)$, $\mathrm{MW}=132.16 \mathrm{~g} / \mathrm{mol}, \mathrm{d}=1.048 \mathrm{~g} / \mathrm{mL}$ were purchased from Sigma-Aldrich (St. Louis, MI, USA). Ethanol for analysis (99.5), $\mathrm{MW}=46.07 \mathrm{~g} / \mathrm{mol}, \mathrm{d}=0.790 \mathrm{~g} / \mathrm{mL}$, and dichloromethane $(99.9 \%), \mathrm{MW}=84.93 \mathrm{~g} / \mathrm{mol}$, $\mathrm{d}=1.33 \mathrm{~kg} / \mathrm{L}$, were purchased from Merck (Kenilworth, NJ, USA).

\subsection{Preparation of $\beta-C D$ Inclusion Complexes ( $\beta$-CD-Carvacrol or $\beta$-CD-Cinnamaldehyde).}

The co-precipitation method was used to prepare the inclusion complexes between $\beta-C D$ and the active agents (trans-cinnamaldehyde and carvacrol). Five grams of $\beta-\mathrm{CD}$ and $50 \mathrm{~mL}$ of a 2:1 water/ethanol mixture were placed in a reactor, with stirring at $55^{\circ} \mathrm{C}$. Subsequently, $10 v / v(\%)$ solutions in ethanol of the active agents (trans-cinnamaldehyde or carvacrol) were prepared. The ratio of $\beta-C D$ to active agents was 80:20 (w/w). The solution of the active agents was added dropwise to the $\beta-C D$ solution, mixing at $55{ }^{\circ} \mathrm{C}$ during $30 \mathrm{~min}$. The solution was stirred during $4 \mathrm{~h}$ until its temperature decreased to $25^{\circ} \mathrm{C}$. The final solution was cooled to $7^{\circ} \mathrm{C}$ during $12 \mathrm{~h}$, and the precipitate was recovered by vacuum filtration and dried in an oven at room temperature for $24 \mathrm{~h}$ [22]. 


\subsection{Inclusion Complex Characterization}

\subsubsection{Surface Analysis}

The samples (inclusion complexes and the LDPE surface of the films) were analyzed by scanning electronic microscopy (SEM) on a Zeiss EVO-MA10 apparatus (Oberkochen, Germany), with a resolution of $3000 \times$ in a nitrogen atmosphere, and previously treated with gold. First, the inclusion complexes were filtered and washed 3 times with dichloromethane to remove the residual essential oil. Then, $2.5 \mathrm{mg}$ was powdered and observed in SEM. The size was determined by the software named image (1.52d version), with an average of 50 complexes and a standard deviation of \pm 0.85 . For the LDPE composites surface test, a $15 \mathrm{~mm} \times 15 \mathrm{~mm} \times 1 \mathrm{~mm}$ piece of the films of was cut and observed frontally to analyze the oil and the inclusion complex on the surface LDPE. In parallel, in the case of the $\mathrm{LDPE}+\beta-\mathrm{CD}$ cinnamaldehyde inclusion complex, a cross-section of the film was made to corroborate the presence of occluded inclusion complexes within the matrix.

\subsubsection{Infrared Analysis}

Fourier Transform Infrared (FTIR) analysis was performed on a Perkin Elmer BX-FTIR spectrometer (Waltham, MA, USA). The IR spectra were collected in the 4000 to $500 \mathrm{~cm}^{-1}$ range, with a resolution of $4 \mathrm{~cm}^{-1}$ at room temperature and a scanning rate of $1 \mathrm{~cm} / \mathrm{s}$, taking 32 counts per measurement, and the sample:KBr ratio was 1:10.

\subsubsection{Encapsulation Yield and Efficiency}

Encapsulation yield (E.Y.) and encapsulation efficiency (E.E.) in $\beta$-CD were studied for trans-cinnamaldehyde and carvacrol. First, a calibration curve was prepared considering 10 points, between $10 \%$ and $100 \%$ of oil used in dichloromethane (DCM). Then, $0.5 \mathrm{~g}$ of the inclusion complexes were powdered, and washed 3 times with DCM to extract residual oil remain on the surface. The sample was dissolved in $20 \mathrm{~mL}$ of distilled water and left under sonication during 30 min to solubilize the $\beta$-cyclodextrin. The encapsulated oil was separated from the solution using $10 \mathrm{~mL}$ of dichloromethane DCM. The organic phase was recovered and stored in $10 \mathrm{~mL}$ vials. Inclusion complexes were quantified on a UV-visible Weisser SPECORD 100 spectrophotometer (Analytik Jena AG/ Jena/Germany) at $280 \mathrm{~nm}$. The values of E.Y. and E.E. were obtained by extrapolating the values obtained by means of the previously prepared curve and using the following equations [23].

$$
\text { E.E. }=\frac{\text { amount of active compound entrapped }}{\text { initial amount of active compound }} \times 10
$$

where "amount of active compound entrapped" is the amount of compound present in the inclusion complex particles and "initial amount of active compound" indicates the amount of compound initially used to manufacture the inclusion complex particles.

The encapsulation yield (E.Y.) is a ratio of the mass of inclusion complex obtained and the number of reagents used. The E.Y. serves to quantify the efficiency of the encapsulation of the active agents. The determination is shown in the following equation:

$$
\text { E.Y. }=\frac{\text { amount of inclusion complex obtained }}{\text { initial amount of reagents used }} \times 100
$$

\subsection{Preparation of Polymer/Active Agent Compound by the Melting Process}

The mixtures were made in a double screw Brabender equipment (GmbH\&Co.KG, Duisburg, Germany) previously heated to $115^{\circ} \mathrm{C}$, the polymer was charged and melted for $5 \mathrm{~min}$ at $12 \mathrm{rpm}$. Then, the speed was increased to $110 \mathrm{rpm}$, and the active agent was added and mixed for $2 \mathrm{~min}$ to obtain a homogeneous mixture. All the process was carried out in a nitrogen atmosphere. The 
various mixtures of LDPE + carvacrol, LDPE + cinnamaldehyde, LDPE + $\beta$-CD-carvacrol, and LDPE + $\beta$-CD-cinnamaldehyde were prepared using $95 \% / 5 \% w / w$, and they were compared with neat LDPE.

Preparation of Films by Melt Pressing

The films were molded by compression at $170{ }^{\circ} \mathrm{C}$ and 50 psi pressure in a Scientific Lab Tech Engineering hydraulic press equipment (Samutprakarn, Thailand). The composites from the process ( $3.5 \mathrm{~g}$ ) were placed in a $12 \times 12$ and $0.1 \mathrm{~cm}$ thick mold, which was pre-pressed for $2 \mathrm{~min}$, and then pressed for $3 \mathrm{~min}$. Finally, the plates were cooled $\left(20^{\circ} \mathrm{C} / \mathrm{min}\right)$ and the film was removed.

\subsection{Fils Characterization}

The films were also characterized by FTIR and SEM analysis as described above.

\subsubsection{Thermal Analysis}

Differential scanning calorimetry (DSC) (Mettler DSC823) was used to analyze the thermal behavior of the samples. The samples were heated from 25 to $200{ }^{\circ} \mathrm{C}$ at a rate of $10{ }^{\circ} \mathrm{C} / \mathrm{min}$ and then cooled to $25^{\circ} \mathrm{C}$ in an inert atmosphere (nitrogen). The values were taken from the second heating curve to eliminate any thermal history. Percent crystallinity $\left(X_{c}\right)$ was determined using Equation (3).

$$
X c(\%)=\frac{\Delta H_{\mathrm{m}}}{(1-\Phi) \Delta H_{0}} \times 100
$$

where $\Delta H \mathrm{~m}$ is the melting enthalpy $(\mathrm{J} / \mathrm{g})$ of the polymer composite, $\Delta H_{0}$ is the value of the enthalpy corresponding to the melting of a $100 \%$ crystalline sample with a value of $293 \mathrm{~J} / \mathrm{g}$ [30], and $\Phi$ is the weight fraction of the active complex in the composite

The polymers' thermal stability was evaluated by thermogravimetric analysis (TGA) using a Netzsch TG Libra 209 in a nitrogen atmosphere with a flow of $10 \mathrm{~mL} / \mathrm{min}$. The samples were heated from 25 to $600{ }^{\circ} \mathrm{C}$ at a rate of $20^{\circ} \mathrm{C} / \mathrm{min}$.

\subsubsection{Mechanical Properties}

The mechanical properties of the materials were determined by tensile-strain tests on an HP Instron D-500 dynamometer at a strain rate of $50 \mathrm{~mm} / \mathrm{min}$ at room temperature. Dumbbell samples with an effective Length, $L_{0}$ of $120.0 \mathrm{~mm}$ and width of $11.6 \mathrm{~mm}$ were prepared by cutting test specimens from a 1-mm thick plate using a steel mold according to ASTM D638 [31]. Each set of measurements was repeated at least four times.

\subsubsection{Active Agent Release}

The release of active agents was analyzed by UV-visible spectroscopy on a UV-Weisser SPECORD100 visible spectrophotometer (Analytik Jena AG, Jena, Germany). For this, pieces of the films of a size of $1.5 \mathrm{~cm} \times 3 \mathrm{~cm} \times 0.1 \mathrm{~cm}$ and $0.5 \mathrm{~g}$ of weight were cut. The samples were placed in a vial with $10 \mathrm{~mL}$ of chromatographic grade water, left to stand for 0 to 9 weeks to then quantify the amount of active agent released.

\subsubsection{Fungicidal Activity}

The strain used in this study was B. cinerea ChFC 09 (Chilean Fungal Collection). The strain was obtained from grapes collected in a vineyard located in Casablanca, Fifth Region, Chile. The fungicidal activity of the films was determined quantitatively by the colony counting method; the samples (composites) and control (neat PE) were cut into $2.5 \mathrm{~cm} \times 2.5 \mathrm{~cm}$ squares and sterilized. They were then placed in sterile saline solution (SF). A solution containing between $1 \times 10^{4}$ and $5 \times 10^{6}$ spores of $B$. cinerea fungus was taken and $500 \mu \mathrm{L}$ were deposited on the surface of the films for $8 \mathrm{~h}$ at room temperature. Subsequently, the films were deposited in $10 \mathrm{~mL}$ of SF, $500 \mu \mathrm{L}$ of the recovered suspension 
was diluted in $4.5 \mathrm{~mL}$ of SF, and $200 \mu \mathrm{L}$ of dilutions were taken and plated on Sabouraud agar plates by the double rake technique, and they were incubated for $96 \mathrm{~h}$ at room temperature. Finally, the colony forming units (CFU) were counted and the reduction percentage was obtained by the following equations:

$$
\% \text { reduction }=\frac{(\mathrm{C}-\mathrm{M}) \times 100}{\mathrm{C}}
$$

where $\mathrm{C}=\mathrm{CFU} / \mathrm{mL}$ control count, and $\mathrm{M}=\mathrm{UFC} / \mathrm{mL}$ sample count.

\section{Results}

\subsection{Inclusion Complex Characterization}

\subsubsection{Morphological Analysis of $\beta$-CD-Carvacrol and Trans-Cinnamaldehyde}

Figure 1 shows the inclusion complex of $\beta-C D$, carvacrol and cinnamaldehyde incorporated into $\beta$-CD (ca. $5 \mu \mathrm{m})$. The inclusion of carvacrol ( $\beta$-CD-carvacrol) presented encapsulation particles of smaller size (ca. $4 \mu \mathrm{m}$ ) than the inclusion complexes with cinnamaldehyde ( $\beta$-CD-cinnamaldehyde) that obtained different sizes of microencapsulated particles having an average of ca. $5 \mu \mathrm{m}$. For both systems, there was some particle agglomeration. The nature of the agglomeration was more homogeneous for the carvacrol complexes and more heterogeneous for cinnamaldehyde, which could affect its size distribution. A similar behavior was found by Hill et al. [23], who explained that large particles seem to attract smaller particles. Small groups of particles were identified in the initial stages of particle agglomeration. The irregular shape was a consequence of the self-assembly of $\beta$-CD [32]. On the other hand, Campos et al. reported that the incorporation of citral oil into $\beta$-CD reduced the size of the particles compared to native $\beta-C D$, pointing to the formation of the inclusion complex due to changes in the crystalline morphology of $\beta-\mathrm{CD}$ [33]. The same morphology and tendency of physicochemical properties were seen in the inclusion of ginger oil into $\beta-C D$ [34]. However, none of the studies reported average sizes of the $\beta$-CD derivatives.

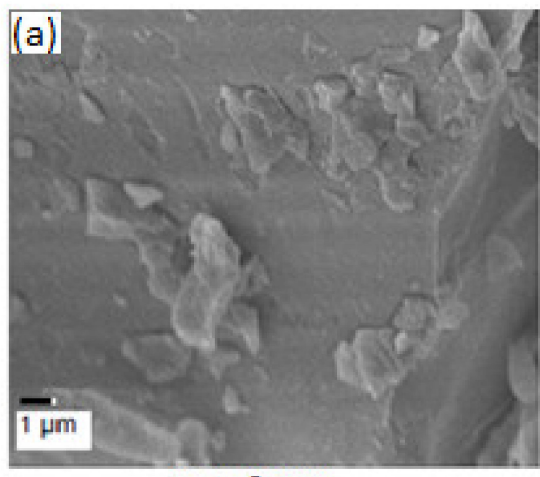

Only $\beta-\mathrm{CD}$

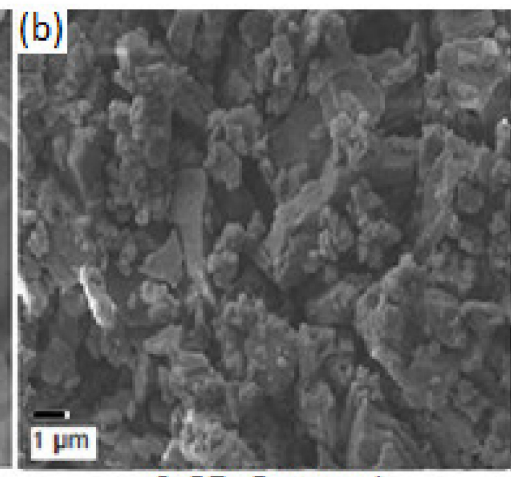

$\beta$-CD-Carvacrol

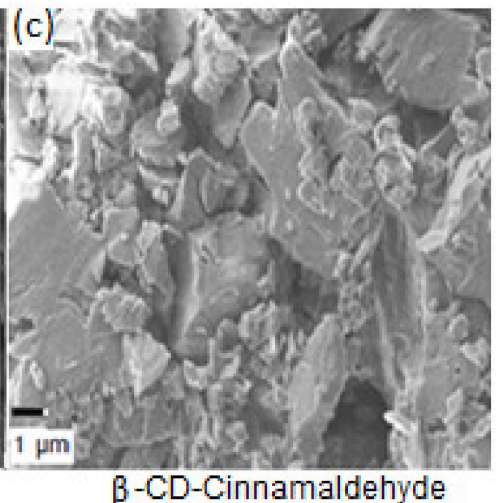

$\beta-\mathrm{CD}$-Cinnamaldehyde

Figure 1. Scanning electron microscopy (SEM) of (a) $\beta-C D$, (b) $\beta$-CD-carvacrol, (c) $\beta$-CDcinnamaldehyde.

\subsubsection{Fourier transform infrared (FTIR) spectroscopy}

FTIR was used to confirm the formation of the inclusion complexes. Figure 2 shows the IR spectra of carvacrol and trans-cinnamaldehyde, $\beta-C D$, and the inclusion complexes $\beta$-CD-carvacrol and $\beta$-CD-cinnamaldehyde. 

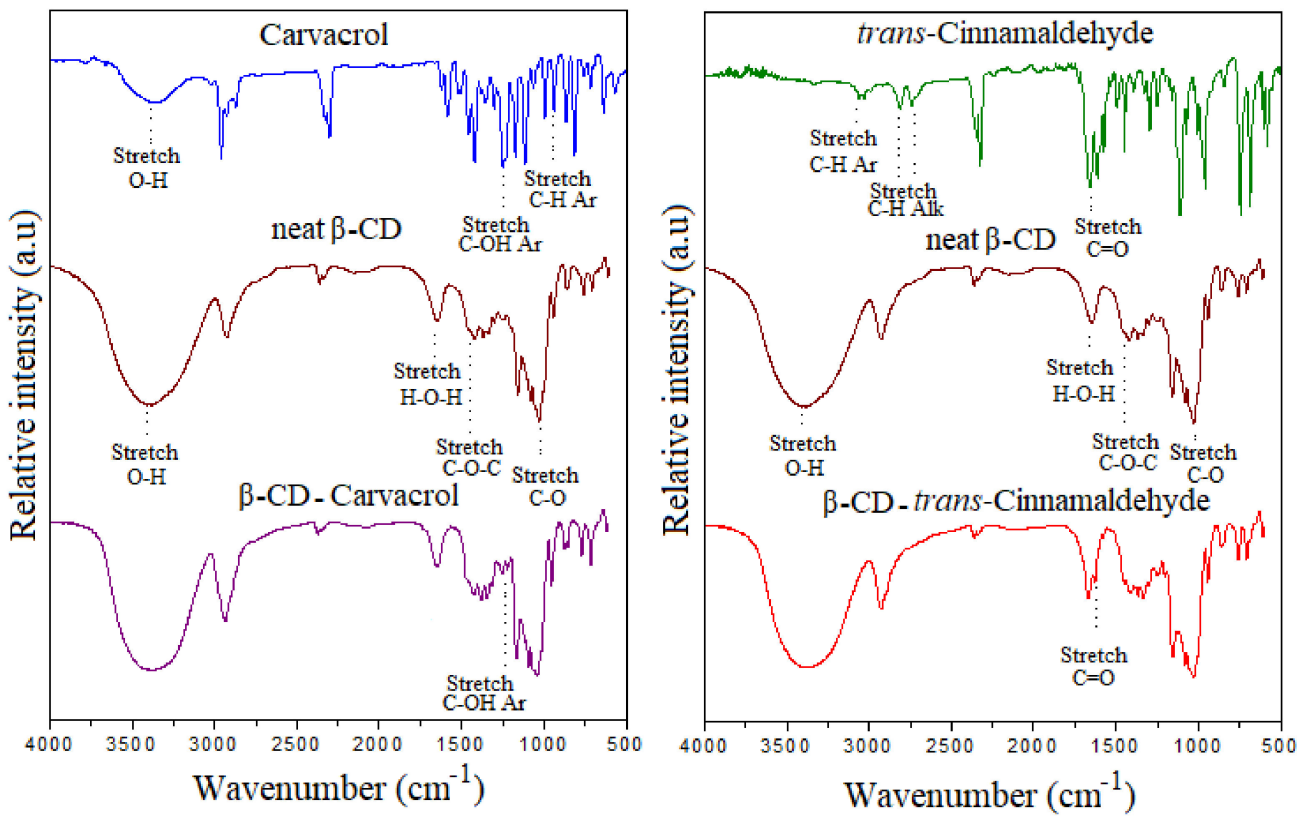

Figure 2. FTIR spectra of carvacrol and trans-cinnamaldehyde, $\beta-C D, \beta-C D / c a r v a c r o l$, and $\beta-\mathrm{CD} /$ cinnamaldehyde.

The signals of carvacrol appear at $3300 \mathrm{~cm}^{-1}$ due to the stretching vibration of $\mathrm{OH}$. The signal at $1260 \mathrm{~cm}^{-1}$ corresponds to the vibration of the aromatic ring $\mathrm{C}-\mathrm{OH}$, and that at $1080 \mathrm{~cm}^{-1}$ to the stretch vibration of aromatic $C=C$. $\beta-C D$ has prominent bands at $3300 \mathrm{~cm}^{-1}$ due to the stretching vibration of $\mathrm{OH}$, the band at $2930 \mathrm{~cm}^{-1}$ is related to the $\mathrm{C}-\mathrm{C}$ stretching vibration of polysaccharides, while $(\mathrm{H}-\mathrm{O}-\mathrm{H})$ at $1648 \mathrm{~cm}^{-1}, 1270 \mathrm{~cm}^{-1}(\mathrm{C}-\mathrm{O}-\mathrm{C})$ is attributed to the asymmetric stretching vibration assigned to the glycosidic bond, and $1030 \mathrm{~cm}^{-1}$ (C-O stretching vibration) [17].

For $\beta-\mathrm{CD} / \mathrm{carvacrol}$, the carvacrol did not have a noticeable shift of the FTIR bands compared to $\beta$-CD. After encapsulation, small signals appear around $1270 \mathrm{~cm}^{-1}$ for the $\beta-C D /$ carvacrol complex which correspond to interactions of $\mathrm{C}-\mathrm{OH}$ from the aromatic ring [34].

The main bands of trans-cinnamaldehyde appear at $3050 \mathrm{~cm}^{-1}$ from the $\mathrm{C}-\mathrm{H}$ stretching of the aromatic ring, the signal at $2980 \mathrm{~cm}^{-1}$ corresponds to $\mathrm{C}-\mathrm{H}$ and $\mathrm{CH}_{2}$ stretching, the band of $2800 \mathrm{~cm}^{-1}$ is due to $\mathrm{CH}$ stretching of the aldehyde group, the signal at $1703 \mathrm{~cm}^{-1}$ corresponds to the carbonyl group $(\mathrm{C}=\mathrm{O})$ stretching [29]. The $\beta$-CD-cinnamaldehyde inclusion complex shows the typical signals for $\beta-C D$, and the carbonyl bands $(C=O)$ appear after the inclusion of trans-cinnamaldehyde in $\beta-C D$. Therefore, the IR analysis showed that the carvacrol and trans-cinnamaldehyde were complexed into $\beta$-CD.

\subsubsection{Encapsulation Yield (E.Y.) and Encapsulation Efficiency (E.E.) of Active compound in the $\beta-C D$}

Table 1 shows the encapsulation yield (E.Y.) and encapsulation efficiency (E.E.) at different stirring speeds. The E.E. it is a quantitative parameter used to calculate the amount of active compound entrapped in the inclusion complex. The results obtained indicate that for both compounds, the stirring speed increases the E.E., indicating that the agitation process facilitates the occlusion in $\beta$-cyclodextrin. Another study reported the entrapment efficiency of trans-cinnamaldehyde at $84.70 \%$ in the $\beta$-CD inclusion complex, similar to that reported in the present study [18]. The encapsulation performance and efficiency of carvacrol were slightly higher than those of trans-cinnamaldehyde at stirring speeds of 500-750 rpm. This may be due to the fact that carvacrol has a better water solubility than cinnamaldehyde, such that the occlusion process is favored compared to cinnamaldehyde [22]. 
Table 1. Encapsulation yield (E.Y.) and encapsulation efficiency (E.E.) of $\beta$-CD inclusion complexes at $280 \mathrm{~nm}$ at different stirring speeds.

\begin{tabular}{ccccc}
\hline \multirow{2}{*}{$\begin{array}{c}\text { Stirring Speed } \\
(\mathbf{r p m})\end{array}$} & \multicolumn{2}{c}{$\beta$-CD-Carvacrol } & \multicolumn{2}{c}{$\beta$-CD-Cinnamaldehyde } \\
\cline { 2 - 5 } & E.Y. (\%) & E.E. (\%) & E.Y. (\%) & E.E. (\%) \\
\hline 250 & 67 & 61 & 65 & 76 \\
500 & 68 & 83 & 68 & 77 \\
750 & 63 & 94 & 68 & 87 \\
1000 & 64 & 92 & 70 & 91 \\
\hline
\end{tabular}

3.2. Film Characterization of Neat LDPE, LDPE + Carvacrol, $L D P E+\beta$-CD-Carvacrol, LDPE + Cinnamaldehyde and $L D P E+\beta-C D$-Cinnamaldehyde

\subsubsection{Infrared Analysis}

Figure 3a shows the IR spectra of neat LDPE, carvacrol, neat $\beta$-cyclodextrin, LDPE + carvacrol and LDPE $+\beta$-CD-carvacrol film. The neat LDPE has the signals corresponding to $\mathrm{CH}_{2}$ stretch at $2930 \mathrm{~cm}^{-1}$, the band at $2860 \mathrm{~cm}^{-1}$ corresponding to $\mathrm{CH}_{2}$ strain vibration, and between $740 \mathrm{~cm}^{-1}$ stretching vibrations of $\mathrm{CH}$ groups [35]. In the case of $\mathrm{PE} /$ carvacrol films, the signals are overlapped with the bands from LDPE. For LDPE $+\beta-C D$-carvacrol films, the characteristic signals of carvacrol appear at $3300 \mathrm{~cm}^{-1}$ due to the presence of the $\mathrm{OH}$ group [36]. The signal at $1270 \mathrm{~cm}^{-1}$ is due to the $\mathrm{C}-\mathrm{O}-\mathrm{C}$ stretching vibration assigned to the glycosidic bond of $\beta-\mathrm{CD}$ [37]. This spectrum shows that the active agents are occluded in the matrix after the mixing and pressing process.
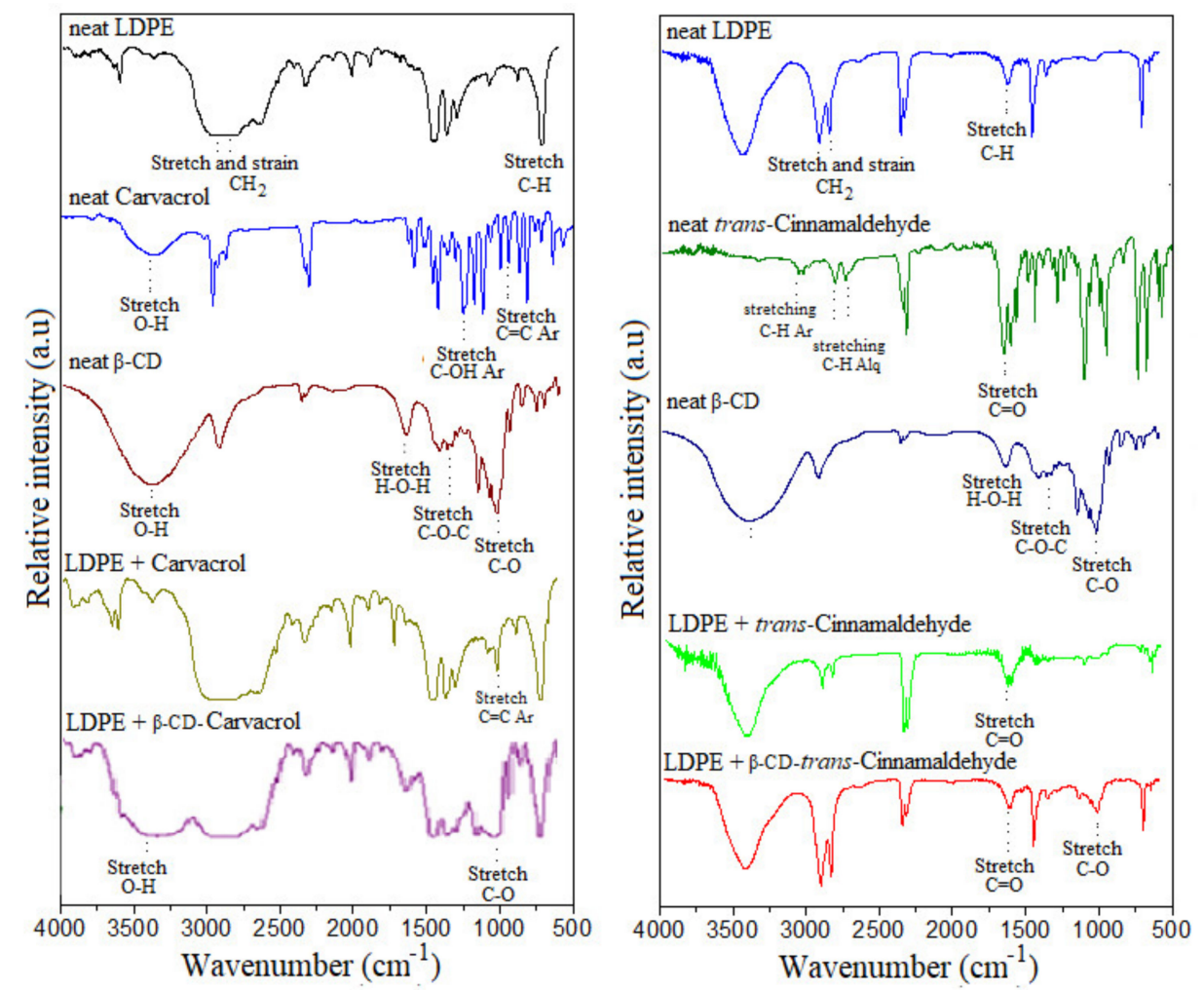

Figure 3. (a) IR spectra of neat LDPE, carvacrol, neat $\beta-C D$, LDPE+carvacrol, and LDPE+ $\beta$-CD-carvacrol film. and (b) IR spectra of neat LDPE, trans-cinnamaldehyde, neat $\beta-C D$, LDPE+cinnamaldehyde, and LDPE+ $\beta$-CD-cinnamaldehyde film.

The FTIR spectra of Figure $3 b$ show the characteristic signals of neat LDPE, $\beta$-cyclodextrin $(\beta-C D)$, trans-cinnamaldehyde, LDPE+cinnamaldehyde and LDPE + $\beta$-CD-cinnamaldehyde. The LDPE + cinnamaldehyde films exhibit a strong signal around $1700 \mathrm{~cm}^{-1}$ corresponding to the stretching band of 
the $\mathrm{C}=\mathrm{O}$ of the aldehyde group. The LDPE $+\beta-\mathrm{CD}$-cinnamaldehyde films present the same signals of trans-cinnamaldehyde $\left(1700 \mathrm{~cm}^{-1}\right)$ from $\mathrm{C}=\mathrm{O}$ and $\beta-\mathrm{CD}\left(1270 \mathrm{~cm}^{-1}\right)$ from $\mathrm{C}-\mathrm{O}-\mathrm{C}$ stretching vibration, confirming the presence of the complex inclusion ( $\beta$-CD-cinnamaldehyde) in the LDPE film $[38,39]$.

\subsubsection{Surface Analysis.}

Figure 4 shows the SEM images of neat LDPE, LDPE+cinnamaldehyde, and LDPE+ $\beta$-CDcinnamaldehyde films. The surfaces of neat LDPE and LDPE+cinnamaldehyde were uniform, and the trans-cinnamaldehyde was homogeneously distributed in the polymer matrix.
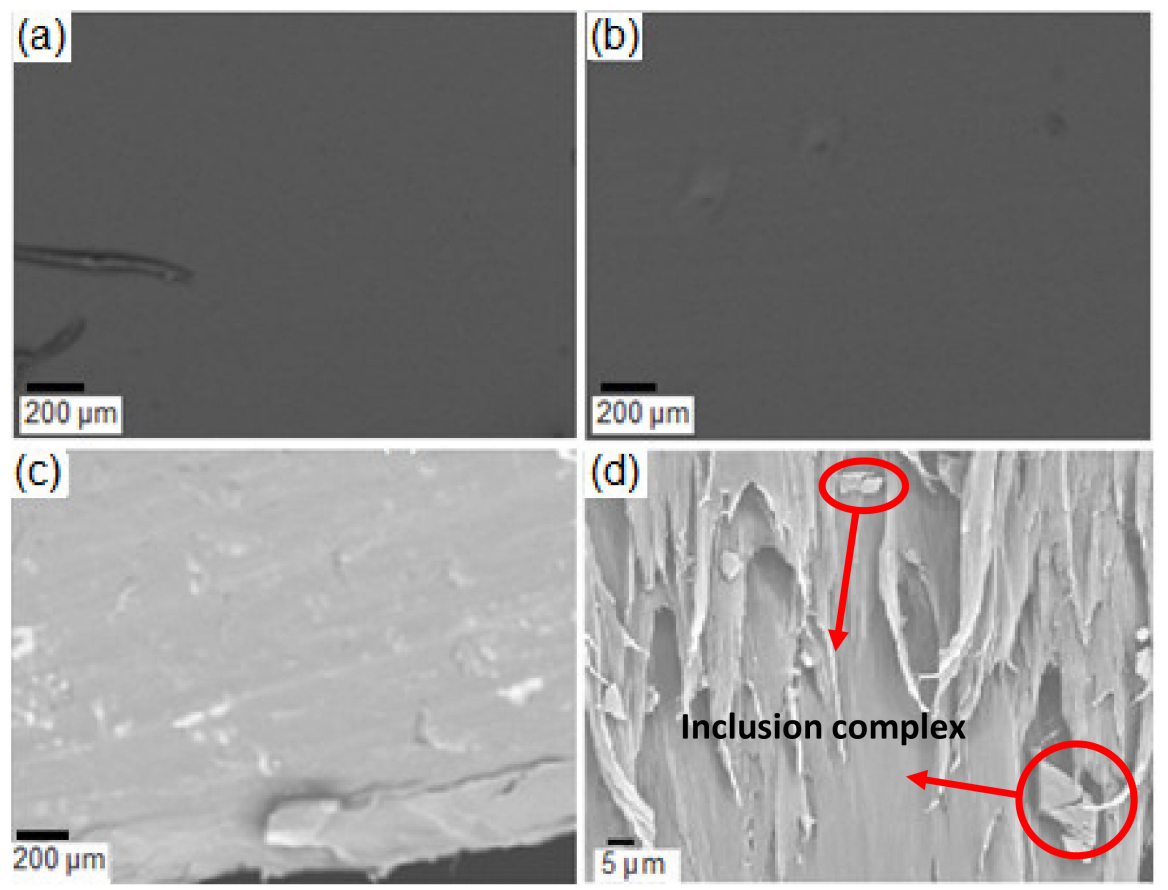

Figure 4. SEM images of (a) Neat LDPE, (b) LDPE+cinnamaldehyde, (c) LDPE+ $\beta$-CD-cinnamaldehyde, and (d) LDPE+ $\beta-C D$-cinnamaldehyde extended cross-section.

For LDPE $+\beta$-CD-cinnamaldehyde films the surface of the films was not homogeneous. This may be attributed to the presence of microcapsules from $\beta-C D$ (Figure 4c). In order to confirm the presence of these microcapsules in the film, a cut of a cross-section was made (Figure $4 \mathrm{~d}$ ), and the image shows that the microcapsules have a size between 5-20 $\mu \mathrm{m}$ distributed on the polymer matrix. Further, there are some zones where the microcapsules were agglomerated.

\subsubsection{Thermal Analysis.}

Table 2 and Figure 5 show the thermal properties obtained by DSC analysis for pure LDPE, trans-cinnamaldehyde, carvacrol, LDPE + carvacrol, LDPE + cinnamaldehyde, LDPE + $\beta$-CD-carvacrol and LDPE $+\beta-C D$-cinnamaldehyde. The pure carvacrol and trans-cinnamaldehyde show peaks at 222 and $243{ }^{\circ} \mathrm{C}$, respectively, due to the evaporation or decomposition of the compound. The melting temperature $(\mathrm{Tm})$ for pure LDPE was determined at $110^{\circ} \mathrm{C}$. The $\mathrm{Tm}$ and percent crystallinity $(\mathrm{Xc})$ of LDPE + active compounds and the films of LDPE $+\beta-C D+$ active compounds showed no change in comparison with pure PE. The values of $T \mathrm{~m}$ and $X \mathrm{c}$ are similar to those reported for LDPE in the literature [40,41]. Mulla et al. studied the effect of clove essential oil (CLO) in linear low-density polyethylene (LLDPE). They also found that the percent crystallinity remained also constant with the CLO incorporations [42]. Sung et al. studied the influence of Allium sativum essential oil (AEO) $(0,2,4,6$ and $8 \mathrm{wt} \%)$ in the LDPE/ethylene-vinyl-acetate (EVA) matrix in the thermal properties. The results show that the melting temperature did not change with the incorporation of different essential 
oils into the polymer matrix [43], but they found an increase of the percent crystallinity and ascribed this behavior to the good affinity of AEO towards the LDPE/EVA polymer. The addition of the EVA component has successfully acted as the compatibilizer between the AEO and LDPE matrix because the latter is a non-polar polymer which is expected to be incompatible with AEO. On the other hand, Sangsuwan et al. [44] studied the effect of vanillin incorporation into chitosan-methyl cellulose, finding a decrease of the heat fusion. They explained the results as due to the benzene structure interrupting the rearrangement of the polymer chain.

Table 2. Thermal properties by DSC and TGA analysis of $\beta-C D$, inclusion complexes, LDPE, LDPE +5 wt \% (carvacrol or trans-cinnamaldehyde) and LDPE + $\beta$-CD-(carvacrol or trans-cinnamaldehyde).

\begin{tabular}{|c|c|c|c|}
\hline Sample & $T_{\mathrm{m}}\left({ }^{\circ} \mathrm{C}\right)$ & $X_{\mathrm{c}}\left({ }^{\circ} \mathrm{C}\right)$ & $T_{\max }\left({ }^{\circ} \mathrm{C}\right)$ \\
\hline Neat $\beta-C D$ & - & - & 330 \\
\hline Carvacrol & - & - & 183 \\
\hline trans-cinnamaldehyde & - & - & 200 \\
\hline$\beta$-CD-carvacrol & - & - & 285 \\
\hline$\beta$-CD-cinnamaldehyde & - & - & 294 \\
\hline Neat LDPE & 111 & 29 & 475 \\
\hline LDPE + carvacrol & 111 & 29 & 450 \\
\hline LDPE + cinnamaldehyde & 111 & 31 & 476 \\
\hline LDPE + $\beta$-CD-carvacrol & 111 & 29 & 475 \\
\hline $\mathrm{LDPE}+\beta-\mathrm{CD}$-cinnamaldehyde & 111 & 27 & 477 \\
\hline
\end{tabular}

$T_{\mathrm{m}}=$ Melting temperature; $X_{\mathrm{c}}=$ percent crystallinity; $T_{\max }=$ Temperature for the maximum weight loss rate; $-=$ not determined.

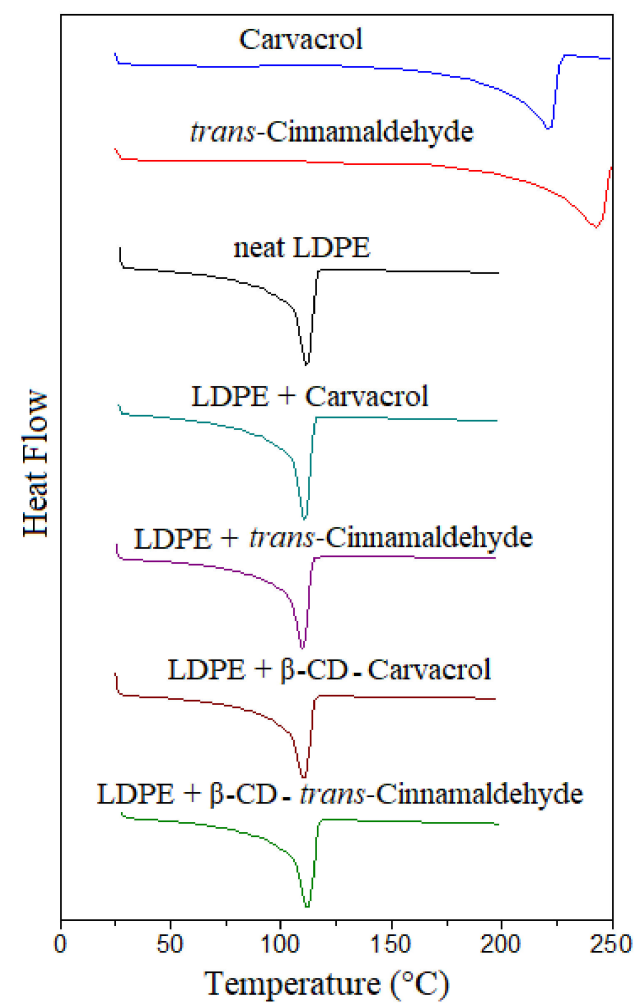

Figure 5. DSC thermograms, neat LDPE, carvacrol, cinnamaldehyde, LDPE + carvacrol, LDPE + cinnamaldehyde, LDPE $+\beta-C D-C a r v a c r o l$ and LDPE $+\beta-C D$-cinnamaldehyde.

Table 2 and Figure 6a shows the TGA curves for carvacrol, trans-cinnamaldehyde, $\beta-C D$, $\beta$-CD-carvacrol and $\beta$-CD-cinnamaldehyde. $\beta$-CD has two peaks, one in the range of $50-82{ }^{\circ} \mathrm{C}$ that is attributed to the release of water molecules, and another one close to $330^{\circ} \mathrm{C}$ corresponding to 
the decomposition of $\beta$-CD. The active compounds (cinnamaldehyde, $200^{\circ} \mathrm{C}$ ) had a higher maximum degradation temperature than carvacrol $\left(180^{\circ} \mathrm{C}\right)$. Further, trans-Cinnamaldehyde contains a conjugated system constituted by a benzene ring and an unsaturated aldehyde, and carvacrol is a monoterpenoid phenol. Thus, trans-Cinnamaldehyde exhibited higher thermal stability than carvacrol due to its greater $\pi$-electron delocalization by resonance [45]. The inclusion complex has one signal at ca. $285-295{ }^{\circ} \mathrm{C}$; therefore, the $\beta-C D$ enhances the thermal stability of the essential oils and the active compounds as described by Wang et al. [46] and Menezes et al. [47]. The TGA results confirm the inclusion of active agents in $\beta$-CD.
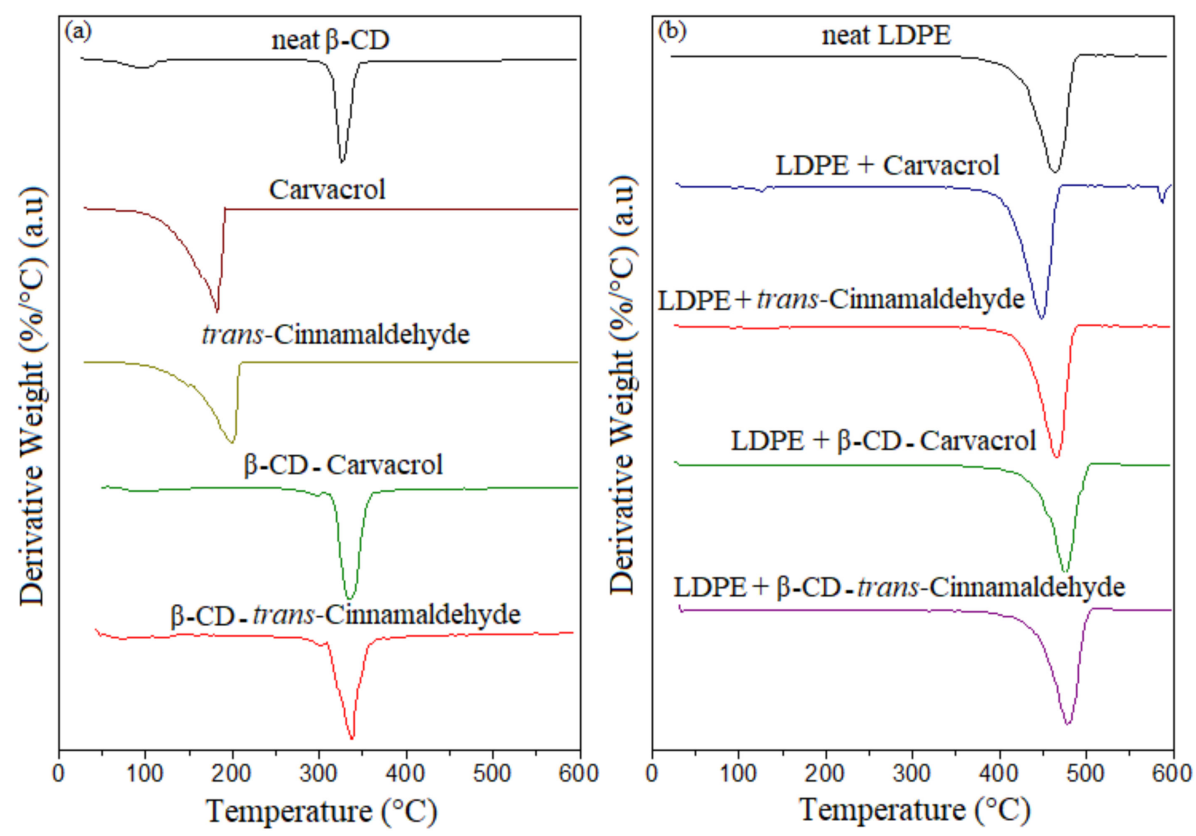

Figure 6. TGA analysis of (a) neat $\beta-C D$, carvacrol, trans-Cinnamaldehyde, $\beta-C D$-Carvacrol, $\beta$-CD-Cinnamaldehyde and (b) neat LDPE, LDPE + Carvacrol, LDPE + trans-Cinnamaldehyde, $\mathrm{LDPE}+\beta-\mathrm{CD}-$ Carvacrol and LDPE $+\beta-\mathrm{CD}$-Cinnamaldehyde.

Table 2 and Figure $6 \mathrm{~b}$ displays the results of the TGA curves for LDPE, $\beta-C D$, LDPE + Carvacrol, and LDPE + cinnamaldehyde, LDPE + $\beta$-CD-carvacrol and LDPE + $\beta$-CD-cinnamaldehyde. The incorporation of the agent active (cinnamaldehyde and carvacrol) or inclusion complexes ( $\beta$-CD-carvacrol or $\beta$-CD-cinnamaldehyde) into LDPE did not change the thermal stability of the LDPE. Similar results were found by da Silva et al. [48], who encapsulated eugenol and linalool essential oils into nanocellulose-poly(butylene adipate-co-terephthalate) (PBAT) active biofilms and thermal stability was similar to that of the neat polymer. Pelissari et al. [49], studied the influence of starch-chitosan with oregano essential oil (OEO) incorporation in the thermal stability of starch-chitosan. The temperature for the maximum weight loss did not change for starch-chitosan-OEO compared to the near matrix. The values of the Tmax ca. $475{ }^{\circ} \mathrm{C}$ correspond to the degradation of the LDPE carbon chain [40].

\subsubsection{Mechanical Properties.}

Table 3 shows the values of Young's modulus $(E)$, yield stress $(\sigma y)$, and deformation at break $\left(E_{\text {Break }}\right)$ for neat LDPE, LDPE + carvacrol, LDPE + cinnamaldehyde with $5 \mathrm{wt} \%$ incorporation of active agents, and LDPE $+\beta$-CD-carvacrol, and LDPE $+\beta$-CD-cinnamaldehyde films with $1 \mathrm{wt} \%$. The polymers show a slight decrement of Young's modulus (12\%) and yield stress compared (14\%) to neat LDPE. The decreased in the Young Modulus and Yield Stress were independent of the system active agent (carvacrol or trans-cinnamaldehyde) or complex $\beta$-CD-(carvacrol or cinnamaldehyde) used. This may be due to the essential oil acting as a plasticizer in the polymer matrix, decreasing the rigidity of the polymer matrix. Similar results were reported by Qin et al. [50] when trans-Cinnamaldehyde was 
incorporated into poly(lactic acid)/poly(trimethylene carbonate). The cinnmaldehyde's incorporation in the polymer presented a better ductility due to phase slipping induced by the low molecular weight additive incorporated into the polymer matrix. Persico et al. [51] prepared nancocomposites based on low density polyethylene with montmorillonite nanoclays and carvacrol. They found that the carvacrol acted as plasticizer, decreasing the elastic modulus and tensile strength.

Table 3. Mechanical properties of LDPE and LDPE + active compounds (trans-cinnamaldehyde or carvacrol) and LDPE + $\beta$-CD-active compound.

\begin{tabular}{cccc}
\hline Sample & $\boldsymbol{E} \mathbf{( M P a )}$ & $\boldsymbol{\sigma y} \mathbf{( M p a )}$ & $\boldsymbol{E}_{\text {Break }} \mathbf{( \% )}$ \\
\hline LDPE & $227 \pm 1$ & $8.9 \pm 0.5$ & $53.3 \pm 7.5$ \\
LDPE+carvacrol & $200 \pm 6$ & $6.8 \pm 0.1$ & $41.4 \pm 1.1$ \\
LDPE+ trans-cinnamaldehyde & $208 \pm 5$ & $7.6 \pm 0.2$ & $44.5 \pm 3.8$ \\
LDPE+ $\beta$-CD-carvacrol & $208 \pm 2$ & $7.4 \pm 0.4$ & $43.4 \pm 4.9$ \\
LDPE+ $\beta-C D-$ cinnamaldehyde & $207 \pm 3$ & $7.4 \pm 0.8$ & $54.5 \pm 6.9$ \\
\hline
\end{tabular}

$E=$ Young's Modulus; $\sigma y=$ Yield stress; $E_{\text {Break }}=$ deformation at break.

Other authors explained the behavior in the decrease of the mechanical properties due to poor interaction between polymer and active agent effects. Sung et al. [43] studied the influence of Allium sativum essential oil (AEO) $(0,2,4,6$, and $8 \mathrm{wt} \%)$ in the LDPE/ethylene-vinyl-acetate (EVA) matrix. The tensile strength (TS) of the films decreased gradually with the higher amount of AEO incorporated. The authors postulated that the polyethylene matrix can tolerate small quantities of existing AEO. The small amount of AEO has good compatibility with the polymer matrix. With high levels of AEO agent incorporated, the space within amorphous region is filled and the agent will start filling the crystalline region and interfering with the polymer-polymer interactions. Large amounts of the EO would lead to agglomeration in the polymer chains and contribute to reducing the TS. Similar results were found by Dong et al. [52] who studied the effect on the mechanical properties of the active packaging film bilayer structure based on low-density polyethylene (LDPE) incorporated with rosemary essential oil (REO) and cinnamon essential oil (CEO). Compared to the control film, the tensile strength of films containing REO or CEO decreased slightly.

The deformation at break of LDPE films with trans-cinnamaldehyde and carvacrol, and their corresponding inclusion complexes with $\beta-\mathrm{CD}$, did not change compared to neat LDPE.

\subsubsection{Active Agent Release}

Figure 7 shows the release of the active compound (carvacrol and trans-cinnamaldehyde) from LDPE films: For this study, 1-9 weeks were considered as the time of analysis of the release of active agents. The results show that all the films released the active agents during the evaluation time. The dependence between the amount of active agent and the release is known. The release of the active agent from the polymer increases with the amount of the incorporated active agent [9]. The LDPE + active agent system $(5 \mathrm{wt} \%)$ showed a greater release of active agent over time than the LDPE + $\beta$-CD-carvacrol and LDPE $+\beta-C D$-cinnamaldehyde $(1 \mathrm{wt} \%)$ active agent films. However, the active release of the agent from the LDPE $+\beta-C D$-carvacrol and LDPE $+\beta$-CD-cinnamaldehyde films was slightly lower than expected in the first three weeks. This behavior could be due to the slow migration of the active agent through the $\beta-C D$ in the first days.

The release of the active agent from LDPE + (carvacrol or trans-cinnamaldehyde) reaches its maximum in the first days (1-2 weeks) and decreases over time, which could be due to the active agent on the surface of the sample. The amorphous layers near the surface can accommodate more water molecules, resulting in a greater release of active agent. A similar behavior was obtained from the silver and zinc oxide nanoparticles $[8,10]$. The active agent release from LDPE $+\beta-C D+$ active compound increased slowly during the first weeks (1-6) due to the slow migration of active agent through the 
$\beta-C D$ and the amorphous part of the specimen films. The LDPE + carvacrol films show an increase in the release of carvacrol during the first three weeks, reaching a maximum close to $1.0 \mu \mathrm{L} / \mathrm{mL}$, then the release gradually decreased over time. LDPE + cinnamaldehyde presented less release compared to LDPE + carvacrol, reaching a maximum close to $0.40 \mu \mathrm{L} / \mathrm{mL}$ in the first weeks and then decreasing over time. The difference between the two compounds according to Nostro et al. [25] can be attributed to the solubility of the essential oils in water. Carvacrol has a solubility of $830 \mathrm{mg} / \mathrm{L}$ in water compared to trans-cinnamaldehyde with $409 \mathrm{mg} / \mathrm{L}$, which mainly affects the driving force that induces the migration of matrix oils $[53,54]$.
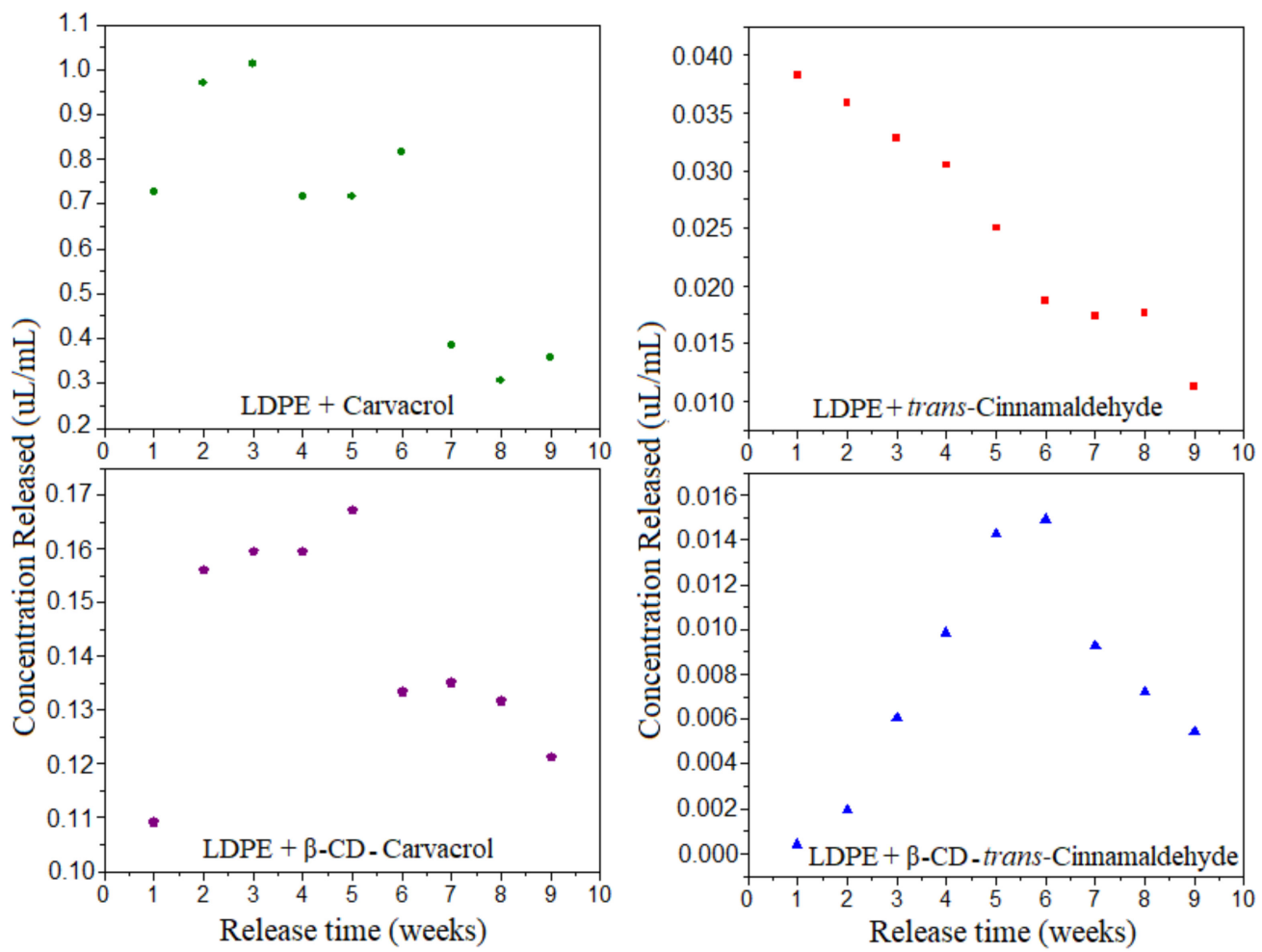

Figure 7. Release of active compounds from the obtained films: LDPE + carvacrol (5 wt \%), LDPE $+\beta$-CD-carvacrol (1 wt \%), LDPE+cinnamaldehyde (5 wt \%), and LDPE + $\beta$-CD-cinnamaldehyde (5 wt \%).

It was also seen that for both cases the release increases in time until it reaches a maximum of 0.17 and $0.15 \mu \mathrm{L} / \mathrm{mL}$ for carvacrol and trans-cinnamaldehyde, respectively. After six weeks, the release of the active compound decreases in time. The release of the agents from the $\beta$-CD cavity is slower and allows a more controlled release compared to non-encapsulated composites

\subsubsection{Fungicidal Activity}

The effect of the direct incorporation of 1 and $5 \mathrm{wt} \%$ of the active agents (carvacrol and trans-cinnamaldehyde), and the corresponding inclusion complexes ( $\beta$-CD-active agent) in loads corresponding to $1 \mathrm{wt} \%$ of the active agent in the polymer matrix, against the fungus $B$. cinerea is summarized in Table 4.

For LDPE with active compounds (carvacrol and trans-cinnamaldehyde), the fungicidal effect increased with the amount of active compounds, showing $99.9 \%$ of fungicidal activity against $B$. cinerea. This may be due to carvacrol and trans-cinnamaldehyde damaging the cell wall, as well as inhibiting the vital enzymes responsible for the synthesis of chitin and glucan, the main components of the wall, causing irreparable damage to the cell that, in turn, causes membrane permeability and the loss of vital cell functions that result in cell death [53,55-57]. 
Table 4. Fungicidal activity of LDPE+active compounds.

\begin{tabular}{ccc}
\hline Sample & $\begin{array}{c}\text { Active Compound * } \\
\text { wt } \%\end{array}$ & $\begin{array}{c}\text { Fungicidal Activity } \\
\text { (\%) }\end{array}$ \\
\hline LDPE + carvacrol & 1 & 45.3 \\
LDPE + cinnamaldehyde & 1 & 25.4 \\
LDPE + carvacrol & 5 & 99.9 \\
LDPE + cinnamaldehyde & 5 & 99.9 \\
LDPE + $\beta$-CD-carvacrol & 1 & 31.4 \\
LDPE + $\beta$-CD-cinnamaldehyde & 1 & 10.9 \\
\hline
\end{tabular}

For LDPE $+\beta-C D$-carvacrol and LDPE $+\beta-C D$-cinnamaldehyde, the fungicidal effect was lower than for polymer films containing an active agent incorporated directly into LDPE, reaching $31.4 \%$ for carvacrol and $10.9 \%$ for trans-cinnamaldehyde that the active compounds are located inside the cavity of $\beta-C D$, and the diffusion through the LDPE matrix is less than that of LDPE + active agent.

Lawtrakul et al. [58] showed that compounds having aromatic rings and $\mathrm{OH}$ groups in their structure form strong interactions with $\beta-C D$, making the release of the active agent towards the surface of the film slower and requiring more time. As was shown in the release study, the nonencapsulated active agents are occluded in the polymer matrix and their diffusion to the surface is much faster and in greater quantity than in the LDPE $+\beta-C D$-active compound, this difference giving rise to the fungicidal activity.

In the case of the LDPE $+\beta-C D$-carvacrol and LDPE $+\beta-C D$-cinnamaldehyde films, they had different biocidal properties, probably due to the nature of the active compound. Yen et al. [59] compared the fungicidal effect of trans-cinnamaldehyde and eugenol, finding that for phenols the fungicidal activity is higher because the interaction of the hydroxyl group $(-\mathrm{OH})$ with the cell membrane is greater than that of the aldehyde group $(-\mathrm{CHO})$, producing greater permeability. Hence, in general, phenolic compounds (carvacrol) are more effective than aldehydes (trans-cinnamaldehyde) in smaller amounts. The materials show the effect of the incorporation of carvacrol and $\beta$-CD-carvacrol in LDPE compared to that of neat LDPE.

\section{Conclusions}

- The co-precipitation method was used successfully to complex the carvacrol or trans-cinnamaldehyde with $\beta$-CD. The encapsulation efficiency (E.E.) increased with stirring speed. This indicates that stirring facilitates the inclusion of the active substances into the cavity of the $\beta-C D$, achieving ca. $90 \%$ E.E. at $750 \mathrm{rpm}$.

- The LDPE + carvacrol and LDPE + cinnamaldehyde showed excellent antifungal effects against B. cinerea with $99 \%$ efficiency. The incorporation of carvacrol, trans-cinnamaldehyde, and their corresponding inclusion complexes with $\beta$-cyclodextrin did not affect the thermal and mechanical properties of LDPE. The release of carvacrol was generally higher than that of trans-cinnamaldehyde, where the factor to be highlighted is the solubility in water-a factor that is directly related to the rate of migration from the polymer matrix. The films containing the inclusion complexes $(\beta-C D)$ have a small biocidal effect, reaching $31.4 \%$ and $10.9 \%$ for the carvacrol and trans-cinnamaldehyde complexes, respectively.

- The biocidal results were related to the release of carvacrol and trans-cinnamaldehyde from the matrix over time. The results confirm the applicability of carvacrol, trans-cinnamaldehyde, and their corresponding inclusion complexes in the preparation of active packaging and its use in the food delivery industry.

Author Contributions: Conceptualization, D.C. and L.M.; Methodology, E.A., L.M, L.M.R, M.Y.-S and M.T.U.; Validation, J.A.O. and F.M.R.; Formal Analysis, D.C. and P.A.Z.; Investigation, P.A.Z. and D.C; Resources, P.A.Z.; Data Curation, D.C. and P.A.Z.; Writing-Original Draft Preparation, D.C and P.A.Z.; Writing-Review \& 
Editing, P.A.Z., D.C. and J.A.O.; Visualization, F.S.; Supervision, P.A.Z.; Project Administration, P.A.Z.; Funding Acquisition, P.A.Z.

Funding: This research was funded by FIA "Fundación para la Innovación Agraria" grant number FIA-PYT-20013-0018 http://www.fia.cl/ and Gobierno Regional Metropolitano de Santiago (GORE-RM). P. A. Zapata acknowledges Basal USA number 1555-Vridei and 021741ZR_PUBLIC projects, Vicerrectoria de Investigación, Desarrollo e Innovación, Universidad de Santiago de Chile.

Acknowledgments: The authors are grateful to Professor Sergio Moya for providing the UV equipment.

Conflicts of Interest: The authors declare no conflict of interest.

\section{References}

1. Rosslenbroich, H.-J.; Stuebler, D. Botrytis cinerea history of chemical control and novel fungicides for its management. Crop Prot. 2010, 19, 557-561. [CrossRef]

2. López-Rubio, A.; Almenar, E.; Hernandez-Muñoz, P.; Lagarón, J.M.; Catalá, R.; Gavara, R. Overview of active polymer-based packaging technologies for food applications. Food Rev. Int. 2004, 20, 357-387. [CrossRef]

3. Bravo, J. Boletín Frutícola, Avance Enero, Publicación de la Oficina de Estudios y Políticas Agrarias (ODEPA); Ministerio de Agricultura, Gobierno de Chile: Santiago, Chile, 2013.

4. Esterio, M.; Auger, J.; Ramos, C.; Araneda, M. Proyecto Innova Chile de CORFO; Código Innova: 07CN13IBM-14; Universidad de Chile: Santiago, Chile, 2013.

5. Clemente, I.; Aznar, A.; Silva, F.; Nerín, C. Antimicrobial properties and mode of action of mustard and cinnamon essential oils and their combination against foodborne bacteria. Innov. Food Sci. Emerg. Technol. 2016, 36, 26-33. [CrossRef]

6. Garavand, F.; Rouhi, M.; Razavi, S.H.; Cacciotti, I.; Mohammadi, R. Improving the integrity of natural biopolymer films used in food packaging by crosslinking approach: A review. Int. J. Biol. Macromol. 2017, 104, 687-707. [CrossRef]

7. Zapata, P.; Palza, H. Polyethylene-based-Bio and nanocomposites for packaging applications. In Polyethylene-Based Biocomposites and Bionanocomposites; Visakh, P.M., Lüftl, S., Eds.; Scrivener Publishing LLC: Beverly, MA, USA, 2016; pp. 365-403, Chapter 10.

8. Zapata, P.A.; Tamayo, L.; Cerda, E.; Páez, M.; Rabagliati, F. Nanocomposites based on polyethylene and nanosilver particles produced by metallocenic "in situ" polymerization: Synthesis, characterization, and antimicrobial behavior. Eur. Polym. J. 2010, 478, 1541-1549. [CrossRef]

9. Yañez, D.; Rabagliati, F.M.; Guerrero, S.; Lieberwirth, I.; Ulloa, M.T.; Gomez, T.; Zapata, P.A. Photocatalytic inhibition of bacteria by $\mathrm{TiO}_{2}$ nanotubes-doped polyethylene composites. Appl. Catal. A 2015, 489, 255-261. [CrossRef]

10. Rojas, K.; Canales, D.; Amigo, N.; Montoille, L.; Cament, A.; Rivas, L.; Gil-Castell, O.; Reyes, P.; Ulloa, M.T.; Ribes-Greus, A.; et al. Effective antimicrobial materials based on Low-density polyethylene (LDPE) with zinc oxide (ZnO) nanoparticles. Compos. Part B 2019, 172, 173-178. [CrossRef]

11. Quijada, R.; Palma, R.; Palza, H. Polypropylene with embedded copper metal or copper oxide nanoparticles as novel plastics antimicrobial agent. Lett. Appl. Microbiol. 2011, 53, 50-54. [CrossRef]

12. Zapata, P.; Delgado, K.; Palza, H.; Rabagliati, F.M. Novel antimicrobial polyethylene composites prepared by metallocenic in situ polymerization with $\mathrm{TiO}_{2}$-based nanoparticles. J. Polym. Sci. 2012, 50, 4055-4062. [CrossRef]

13. Maneerat, C.; Hayata, Y. Antifungal activity of $\mathrm{TiO}_{2}$ photocatalysis against Penicillum expansum in vitro and fruits test. Int. J. Food Microbiol. 2006, 107, 99-103. [CrossRef]

14. Zapata, P.; Palza, H.; Cruz, L.; Lieberwith, I.; Catalina, F.; Corrales, T.; Rabagliati, F. Poliethylene and poly (ethylene-co-1-octadecene) composites with $\mathrm{TiO}_{2}$ based nanoparticles by metallocene in situ polymerization. Polymer 2013, 54, 2690-2698. [CrossRef]

15. Burt, S. Essential oils: Their antibacterial properties and potential applications in foods-A review. Int. J. Food Microbiol. 2004, 94, 223-253. [CrossRef]

16. Caccioti, I.; Mori, S.; Cherubini, V.; Nanni, F. Eco-sustainable systems based on poly (lactic acid), diatomite and coffee grounds extract for food packaging. Int. J. Biol. Macromol. 2018, 112, 567-575. [CrossRef]

17. Wang, T.; Li, B.; Si, H.; Lin, L.; Chen, L. Release Characteristics and antibacterial activity of solid state eugenol/ $\beta$-Cyclodextrin inclusion complex. J. Incl. Phenom. Macrocycl. Chem. 2011, 71, 207-213. [CrossRef] 
18. Zhang, Y.; Liu, X.; Wang, Y.; Jiang, P.; Siew Young, Q. Antibacterial activity and mechanism of cinnamon essential oil against Escherichia coli and Staphylococcus aureus. Food Control 2016, 59, 282-289. [CrossRef]

19. Vahedikia, N.; Garavand, F.; Tajeddin, B.; Cacciotti, I.; Jafari, S.; Omidi, T.; Zahedi, Z. Biodegradable zein film composites reinforced with chitosan nanoparticles and cinnamon essential oil: Physical, mechanical, structural and antimicrobial attributes. Colloids Surf. B Biointerfaces 2019, 177, 25-32. [CrossRef]

20. Chen, H.; Li, L.; Ma, Y.; Mcdonald, T.P.; Wang, Y. Development of active packaging film containing bioactive components encapsulated in $\beta$-cyclodextrin and its application. Food Hydrocoll. 2019, 90, 360-366. [CrossRef]

21. Cheng, M.; Wang, J.; Zhang, R.; Kong, R.; Lu, W.; Wang, X. Characterization and application of the microencapsulated carvacrol/sodium alginate films as food packaging materials. Int. J. Biol. Macromol. 2019, 141, 259-267. [CrossRef]

22. Petrovic, G.; Stojanovic, G.; Radulovic, N. Encapsulation of cinnamon oil in $\beta$-Cyclodextrin. J. Med. Plants Res. 2010, 4, 1382-1390. [CrossRef]

23. Hill, L.; Gomez, C.; Tylor, T. Characterization of beta-Cyclodextrin inclusion complex containing essential oils (trans-cinnamaldehyde, eugenol, cinnamon bark, and clove bud extracts) for antimicrobial delivery applications. Food Sci. Technol. 2013, 51, 86-93. [CrossRef]

24. Kordali, S.; Cakir, A.; Ozer, H.; Cakmakci, R.; Mete, E. Antifungal phytotoxic and insecticidal properties of essential oils isolated from Turkish Origanum acutidens and its three components, carvacrol, thymol and p-cymene. Bioresour. Technol. 2008, 99, 8788-8795. [CrossRef]

25. Nostro, A.; Scaffaro, R.; D’Arrigo, M.; Botta, L.; Filocamo, A.; Marino, A.; Bisignano, G. Study on carvacrol and cinnamaldehyde polymeric films: Mechanical properties, release kinetics and antibacterial and antibiofilm activities. Appl. Microbiol. Biotechnol. 2012, 96, 1029-1038. [CrossRef]

26. Szente, L.; Szejtli, C. Cyclodextrin as food ingredients. Trends Food Sci. Technol. 2004, 15, 137-142. [CrossRef]

27. Kader, E.; Aggor, A. Microencapsulation of Flaxseed Oil by $\beta$-Cyclodextrin. J. Appl. Sci. Res. 2013, 9, 2951-2958.

28. Wen, P.; Zhu, D.-H.; Feng, D.; Liu, F.-J.; Lou, W.-Y.; Li, N.; Zong, M.-H.; Wu, H. Fabrication of electrospun polylactic acid nanofilm incorporating cinnamon essential oil/ $\beta$-cyclodextrin inclusion complex for antimicrobial packaging. Food Chem. 2016, 196, 996-1004. [CrossRef]

29. Chen, G.; Liu, B. Cellulose sulfate based film with slow-release antimicrobial properties prepared by incorporation of mustard essential oil and $\beta$-cyclodextrin. Food Hydrocoll. 2016, 55, 100-107. [CrossRef]

30. Wei, L.; Tang, T.; Huang, B. Synthesis and characterization of polyethylene/clay-silica nanocomposites: A montmorillonite/silica-hybrid-supported catalyst and in situ polymerization. J. Polym. Sci. Part A Polym. Chem. 2004, 42, 941-949. [CrossRef]

31. Kormin, S.; Kormin, F.; Beg, M.; Piah, M. Physycal and mechanical properties of LDPE incorporated with different starch souces. In IOP Conference Series: Materials Science and Engineering; IOP Publishing: Bristol, UK, 2017; Volume 226, p. 012157. [CrossRef]

32. Kotronia, M.; Kavetzou, E.; Loupassaki, S.; Kikionis, S.; Vouyiovka, S.; Detsi, A. Encapsulation of Oregano (Origanum onites L.) Essential Oil in $\beta$-Cyclodextrin ( $\beta-C D)$ : Synthesis and Characterization of the Inclusion Complexes. Bioengineering 2017, 4, 74. [CrossRef]

33. Campos, C.A.; Lima, B.S.; Trindade, G.G.G.; Souza, E.P.B.S.S.; Heimfarth, L.; Quintans, J.S.S.; Quintans-Junior, L.J.; Sussuchi, E.M.; Sarmiento, V.H.V.; Carvalho, F.M.S.; et al. Anti- hyperalgesic and anti-inflammatory effects of citral with $\beta$-cyclodextrin and hydroxypropyl- $\beta$-cyclodextrin inclusion complexes in animal models. Life Sci. 2019, 229, 139-148. [CrossRef]

34. Zhang, Y.; Zhang, H.; Wang, F.; Wang, L.X. Preparation and properties of ginger essential oil $\beta$-cyclodextrin/chitosan inclusion complexes. Coatings 2018, 8, 305. [CrossRef]

35. Reesha, K.V.; Panda, S.K.; Bindu, J.; Varghese, T.O. Development and characterization of an LDPE/chitosan composite antimicrobial film for chilled fish storage. Int. J. Biol. Macromol. 2015, 79, 934-942. [CrossRef]

36. Arrieta, M.P.; Peltzer, M.A.; Garrigós, M.; Jiménez, A. Structure and mechanical properties of sodium and calcium caseinate edible active films with carvacrol. J. Food Eng. 2013, 114, 486-494. [CrossRef]

37. Cannavà, C.; Crupi, V.; Ficarra, P.; Guardo, M.; Majolino, D.; Stancanelli, R.; Venuti, V. Physicochemical characterization of coumestrol/ $\beta$-cyclodextrins inclusion complexes by UV-vis and FTIR-ATR spectroscopies. Vib. Spectrosc. 2008, 48, 172-178. [CrossRef]

38. Yang, Z.; Chai, K.; Ji, H. Selective inclusion and separation of cinnamaldehyde and benzaldehyde by insoluble $\beta$-cyclodextrin polymer. Sep. Purif. Technol. 2011, 80, 208-2016. [CrossRef] 
39. Muller, J.; González-Martínez, C.; Chiralt, A. Poly(lactic) acid (PLA) and starch bilayer films, containing cinnamaldehyde, obtained by compression moulding. Eur. Polym. J. 2017, 95, 56-70. [CrossRef]

40. Murray, K.; Kennedy, J.; McEvoy, B.; Vrain, O.; Ryan, D.; Higginbotham, C. The effects of high energy electron beam irradiation on the thermal and structural properties of low density polyethylene. Radiat. Phys. Chem. 2012, 81, 962-966. [CrossRef]

41. Petterson, P.; Vyazovkin, S.; Wight, C. Kinetics, thermal and thermo-oxidative degradation of polystyrene, polyethylene and poly(propylene). Macromol. Chem. Phys. 2001, 202, 775-784. [CrossRef]

42. Mulla, M.; Ahmed, J.; Al-Attar, H.; Castro-Aguirre, E.; Arfat, Y.; Auras, R. Antimicrobial efficacy of clove essential oil infused into chemically modified LLDPE film for chicken meat packaging. Food Control 2017, 63, 663-671. [CrossRef]

43. Sung, S.; Sin, L.; Tee, T.; Bee, S.; Rahmat, A.R. Effects of Allium sativum essence oil as antimicrobial agent for food packaging plastic film. Innov. Food Sci. Emerg. Technol. 2014, 26, 406-414. [CrossRef]

44. Sangsuwan, J.; Rattanapanone, N.; Rachtanapun, P. Effects of vanillin and plasticizer on properties of chitosan-methyl cellulose based film. Appl. Polym. Sci. 2008, 109, 3540-3545. [CrossRef]

45. Yeh, H.F.; Luo, C.Y.; Lin, C.Y.; Cheng, S.S.; Hsu, Y.R.; Chang, S.T. Methods for Thermal Stability Enhancement of Leaf Essential Oils and Their Main Constituents from Indigenous Cinnamon (Cinnamomum osmophloeum). J. Agric. Food Chem. 2013, 61, 6293-6298. [CrossRef]

46. Wang, J.; Cao, Y.; Sun, B.; Wang, C. Physicochemical and release characterization of garlic oil $\beta$-Cyclodextrin inclusion complex. Food Chem. 2011, 127, 1680-1685. [CrossRef]

47. Menezes, P.; Serafini, R.; Barbosa, Y.; Soares, D.; Santos, B.; Quintans-Júnior, L.; Neves, R.; Mendonca, T.; Rodrigues, A.; Scotti, L.; et al. Kinetic and physical-chemical study of the inclusion complex of $\beta$-Cyclodextrin containing carvacrol. J. Mol. Struct. 2016, 1125, 323-330. [CrossRef]

48. Da Silva, C.G.; Kano, F.S.; dos Santos Rosa, D. Thermal stability of the PBAT biofilms with cellulose nanostructures/ essential oils for active packaging. J. Therm. Anal. Calorim. 2019. [CrossRef]

49. Pelissari, F.; Grossmann, M.; Yamashita, F.; Pineda, E. Antimicrobial, Mechanical, and Barrier Properties of Cassava Starch-Chitosan Films Incorporated with Oregano Essential Oil. J. Agric. Food Chem. 2009, 57, 7499-7504. [CrossRef]

50. Qin, Y.; Yang, J.; Xue, J. Characterization of antimicrobial poly (lactic acid)/ poly (trimethylene carbonate) films with cinnamaldehyde. J. Mater. Sci. 2015, 50, 1150-1158. [CrossRef]

51. Persico, P.; Ambrogi, V.; Carfanga, C.; Cerruti, P.; Ferrocino, I.; Mauriello, G. Nanocomposite polymer films containing carvacrol for antimicrobial active packaging. Polym. Eng. Sci. 2009, 49. [CrossRef]

52. Dong, Z.; Xu, F.; Ahmed, I.; Li, Z.; Lin, H. Characterization and preservation performance of active polyethylene films containing rosemary and cinnamon essential oils for Pacific white shrimp packaging. Food Control 2018, 92, 37-46. [CrossRef]

53. Chen, H.; Davidson, P.M.; Zhong, Q. Impacts of sample preparation methods on solubility and antilisterial characteristics of essential oil components in milk. Appl. Environ. Microbiol. 2014, 80, 907-916. [CrossRef]

54. Ashakirin, S.N.; Tripathy, M.; Patil, U.K.; Majeed, B.A. Chemistry and bioactivity of cinnamaldehyde: A natural molecule medicinal importance. Int. J. Pharm. Sci. Res. 2017, 8, 2333-2340. [CrossRef]

55. Amini, M.; Safaie, N.; Salmani, M.J.; Shams-Bakhsh, M. Antifungal activity of three medicinal plant essential oil against some phytopathogenic Trakia. J. Sci. 2012, 10, 1-8.

56. Cheng, S.S.; Liu, J.Y.; Hsui, Y.R.; Chang, S.T. Chemical polymorphism and antifungal activity of essential oils from leaves of different provenances of indigenous cinnamon (Cinnamomum osmophloeum). Bioresour. Technol. 2006, 97, 306-312. [CrossRef]

57. Cheng, S.S.; Liu, J.Y.; Chang, E.H.; Chang, S.T. Antifungal activity of cinnamaldehyde and eugenol con- geners against wood-rot fungi. Bioresour. Technol. 2008, 99, 5145-5149. [CrossRef]

58. Lawtrakul, L.; Inthajak, K.; Toochinda, P. Molecular calculations on $\beta$-cyclodextrin inclusion complexes with five essential oil compounds from Ocimun basilicum (Sweet Brasil). Sci. Asia 2014, 40, 145-151. [CrossRef]

59. Yen, T.B.; Chang, S.T. Synergistic effects of cinnamaldehyde in combination with eugenol against wood decay fungi. Bioresour. Technol. 2008, 99, 232-236. [CrossRef]

(C) 2019 by the authors. Licensee MDPI, Basel, Switzerland. This article is an open access article distributed under the terms and conditions of the Creative Commons Attribution (CC BY) license (http://creativecommons.org/licenses/by/4.0/). 